\title{
INCLUSÃO NA AGENDA PÚBLICA, ATIVISMO RELIGIOSO E RETROCESSOS NOS DIREITOS SEXUAIS E REPRODUTIVOS: O CASO DO ABORTO
}

\section{João Bôsco Hora Göis'}

Resumo: Este artigo examina como o ingresso na agenda pública não assegura que um dado problema social permaneça nela. Para tanto, discute os ataques aos direitos reprodutivos e sexuais, principalmente os realizados por parlamentares do Congresso Nacional vinculados a religiões cristãs. Os dados para esse artigo foram coletados de diferentes fontes, como relatórios legislativos e projetos de lei. $O$ exame dessas fontes mostra que os ataques contra os direitos sexuais e reprodutivos estão em ascensão e servem para dar suporte a uma ampla agenda regressiva. Mostra, igualmente, que os direitos em questão detêm uma posição instável na agenda pública.

Palavras-chave: Direitos sexuais e reprodutivos; aborto; religião.

ABSTRACT: This article examines how social issues becoming part of the public agenda does not ensure their permanence. To discuss this topic, we analyze the attacks against reproductive and sexual rights, mainly those committed by congressmen and congresswomen affiliated to christian religion. Data were collected from different sources such as congress reports and proposed bills. The examination of such sources shows that attacks against sexual and reproductive rights have increased and serve to support a broader regressive agenda. It also sheds light to the fact that the aforementioned rights hold an unstable position in the public agenda.

Keywords: Sexual and reproductive rights; abortion; religion.

\section{Introdução}

A literatura especializada acolhe como certa a existência do que se convencionou chamar de ciclo de produção de políticas públicas (KINGDON, 1984; SECCHI, 2010). A primeira etapa desse ciclo envolve identificar e reconhecer o "problema", aqui entendido como situação que requer

Doutor em Serviço Social pela Pontificia Universidade Católica de São Paulo (PUC/SP). Professor Titular da Escola de Serviço Social da Universidade Federal Fluminense (UFF), Brasil. E-mail: jbhg@uol.com.br. Orcid: 0000-0003-2305-3853 
intervenção estatal. Tal reconhecimento, a seu turno, pode conduzir à inserção do problema na chamada "agenda formal", ou seja, no espaço político e burocrático onde ficam inscritas as situações que se tornam objeto da intervenção.

Uma vez inserido na agenda, geralmente a partir da atuação de um conjunto de atores (movimentos sociais, políticos, membros da burocracia etc.), o "problema" passa a ser mais detidamente examinado quanto às suas características e, principalmente, à melhor forma de solucioná-lo ou mitigar seus efeitos. Decorre disso a elaboração de programas e projetos que tendem a incluir (mesmo que muitas vezes formalmente), por exemplo, mecanismos de articulação intersetorial, controle social e partilha de responsabilidades entre os diferentes niveis de governo. A operacionalização dos programas e projetos em questão, em situações de maior institucionalidade, é geralmente objeto de monitoramento e avaliações que podem conduzir ao seu aprimoramento ou à sua extinção.

Exposto dessa forma, o ciclo de produção de políticas públicas é uma ferramenta útil para analisar as intervenções estatais sobre diferentes expressões da questão social. Todavia, estudos mostram que suas etapas não ocorrem com a linearidade descrita (BOSCHETTI, 2009). Neste artigo, analisamos como isso se dá em uma dessas etapas: a inserção na agenda formal de um dado problema social e as ações dirigidas a ele. Argumentamos que o ingresso na agenda é uma variável frágil para pensar a densidade de uma dada política, uma vez que ele não equivale à permanência, e esta, por sua vez, não é garantia de estabilidade.

Para tanto, a partir do modo como os direitos sexuais e reprodutivos se tornaram alvo de intervenção estatal e da maneira como, ao mesmo tempo, tem sido questionada sua legitimidade como objeto dessa intervenção, examinamos o Estatuto do Nascituro - conjunto de projetos de lei que buscam eliminar todas as possibilidades de realização de aborto legal no Brasil.

Os direitos sexuais e reprodutivos dizem respeito a um amplo conjunto de proteções estatais e sociais relacionadas à autodeterminação dos indivíduos sobre o uso e controle do corpo. No debate atual tais direitos, geralmente, são discutidos tendo em vista dois grupos minoritários: as mulheres e a população LGBT. Um dos atores que tem questionado e atuado fortemente para desestabilizar os direitos sexuais e reprodutivos na agenda pública é o conjunto de parlamentares do Congresso Nacional vinculados 
ao campo religioso cristão, notadamente católicos e protestantes, mas também espíritas kardecistas ${ }^{2}$.

\section{Atores religiosos, campo legislativo e a desconstrução dos direitos sexuais e reprodutivos}

A presença religiosa na política brasileira surge no processo de colonização e ganha força ao longo dos séculos. $\bigcirc$ catolicismo, em franca aliança com as forças colonizadoras, porque definido como a religião oficial do país, desfrutava de uma série de privilégios que favoreciam sua acumulação de poder econômico, político e simbólico. Somente com a primeira constituição republicana, de 1889, esse quadro começou a mudar significativamente, ainda que a perda de certos privilégios tenha sido compensada com a manutenção de outros ao longo das décadas seguintes. Além disso, indivíduos fortemente ligados ao clero e à doutrina católica assumiam importantes postos na administração federal e no poder legislativo, influenciando os rumos das mais importantes políticas públicas.

A hegemonia católica somente será contestada de forma mais contundente a partir dos anos 1950, quando aumenta o número de templos e de denominações protestantes. A partir daí o protestantismo passa por diversas modificações de ordem exegética, demográfica e programática: ênfase nas preleções e práticas relacionadas ao dom da cura divina; diferenciação de seu perfil; ascensão do neopentecostalismo; exacerbação do pragmatismo; abrandamento de sua dimensão ascética; valorização de um modelo de gestão empresarial na condução dos templos; ênfase na teologia da prosperidade; intensificação do proselitismo etc. (GIUMBELLI, 2008). Esses fenômenos foram, em grande medida, modelados pelo crescimento do número de fiéis, que, por sua vez, foi capitaneado pelas lideranças protestantes para formar, a partir da década de 1980, um potente bloco político-eleitoral.

A Igreja Universal do Reino de Deus (lurd), por exemplo, já em 1986 iniciou um esforço sistemático para eleger membros para as casas legislativas (ORO, 2003). Dados relativos a 2015 auxiliam a compreender a dimensão da presença de parlamentares com adesão explícita, formal ou não, a credos religiosos. A Frente Parlamentar Evangélica do Congresso Nacional era formada por 198 deputados e quatro senadores. Já a Frente

\footnotetext{
2 Embora destaquemos, com ênfase na atualidade, a ação de grupos religiosos inseridos ou fortemente ligados ao Poder Legislativo Federal, reconhecemos que eventuais backsashes nos direitos sexuais e reprodutivos só ocorrem com o concurso de uma multiplicidade de agentes, a exemplo daqueles ligados à burocracia do Poder Executivo Federal.
} 
Parlamentar Mista Católica Apostólica Romana contava com 214 deputados e cinco senadores.

Católicos, evangélicos e espíritas apresentam divergências doutrinárias significativas no que tange a várias matérias relacionadas à vida pública (política monetária, reforma agrária, previdência social, caráter público ou privado dos serviços sociais etc.). Ao mesmo tempo, tendem a atuar solidariamente em torno do que se pode denominar de "questões morais". Tais questões compreendem tópicos como criminalização da homofobia, nome social para pessoas transgêneras e pesquisas com células-tronco. Lugar de grande destaque é ocupado pelo aborto. Em razão disso, buscamos examinar como esses atores, no parlamento brasileiro, têm atuado para desconstruir os direitos já existentes relacionados à interrupção da gravidez, ao mesmo tempo em que tentam criminalizar os que defendem a possibilidade de tal interrupção.

Nesta análise tentamos explicitar duas dimensões. A primeira delas é o topos dos discursos e medidas legislativas propostas. A segunda diz respeito aos elementos - um conjunto de estereótipos sobre a gravidez, as mulheres, a maternidade, a paternidade e a ideia de pessoa - subjacentes a tais discursos e às práticas que eles querem eliciar.

Esta discussão baseia-se em documentos legislativos de diversos tipos projetos de lei, pareceres, votos em separado, atas de reuniões de comissões, notas taquigráficas de discursos de parlamentares e matérias de jornais. Foi realizada análise temática e, posteriormente, exame dos argumentos desse material. Ainda que tenhamos examinado documentos do Senado, escolhemos focar apenas uma das casas legislativas - a Câmara Federal o que permitiu aprofundar a análise.

$\bigcirc$ documento que inaugurou uma longa discussão sobre o (não) direito ao aborto foi o Projeto de Lei 478/2007 (BRASIL, 2007c), apresentado pelos deputados federais Luiz Bassuma (Partido dos Trabalhadores/BA espírita kardecista) e Miguel Martini (Partido Humanista da Solidariedade/ MG - carismático católico). Durante a tramitação deste projeto, contra a vontade dos autores, foram apensados outros projetos com teor correlato: PL 489/2007 (BRASIL, 2007d), do deputado Odair Cunha (Partido dos Trabalhadores/MG), PL 1763/2007 (BRASIL, 2007b), da deputada Jusmari (Partido da República/BA - evangélica), PL 1413/2007 (BRASIL, 2007a), do deputado Luiz Bassuma (Partido dos Trabalhadores/BA) e PL 3748/2008 (BRASIL, 2008), da deputada Sueli Vidigal (PDT/ES - evangélica). Em seu conjunto, ficaram conhecidos como "Estatuto do Nascituro". 


\section{O Estatuto do Nascituro: pressupostos e propostas}

$\bigcirc$ Estatuto do Nascituro busca alterar legalmente os marcos vigentes e gerar novos parâmetros sobre temas relacionados aos direitos sexuais e reprodutivos, notadamente o aborto, mas também a reprodução assistida, as pesquisas com células-tronco e o acesso a métodos contraceptivos.

O principal fundamento que organiza as propostas contidas no Estatuto é a ideia de "nascituro". Há diferentes posições sobre tal ideia. Contudo, predomina no debate científico a visão neurológica que admite a equivalência entre feto e pessoa quando há sistema nervoso central e atividade cerebral, o que pode ocorrer entre a oitava e a vigésima semana de gestação (BARCHIFONTAINE, 2010).

Distanciando-se das tendências predominantes no debate científico contemporâneo, o Estatuto alinha-se à perspectiva que reconhece a existência da vida humana quando do encontro do espermatozoide com o óvulo. Uma vez ocorrido tal encontro, estaríamos diante de um "ser humano concebido, mas ainda não nascido" (BRASIL, 2007c) e de uma "pessoa em desenvolvimento" (BRASIL, 2014). Porque assim conceituado, ao nascituro é atribuída a condição de portador de todos os direitos - à vida, à integridade física, à honra, à imagem etc. - próprios aos indivíduos com personalidade jurídica. Essa definição tanto coloca-se como obstáculo para ampliar as possibilidades de realizar o aborto no país como incide, desconstruindo-as, sobre as já existentes. Dito de outra forma, torna o aborto proibido em qualquer momento da gestação, mesmo nos primeiros dias, e sob quaisquer circunstâncias sob a qual ela tenha se dado. Nesse sentido, podemos afirmar que a ação desses parlamentares buscava desestabilizar e excluir o direito ao aborto da agenda pública de direitos.

Para tanto, o conjunto dos projetos que constitui o Estatuto recorre ao discurso dos direitos humanos, enfatizando, como já referido, a condição de plenitude do indivíduo que já existiria como decorrência da fertilização do óvulo pelo espermatozoide. Além disso, busca amparo na legislação constitucional e infraconstitucional - em seus argumentos contra a discriminação de qualquer "pessoa", condição atribuída ao feto -, assim como em tratados internacionais dos quais o Brasil é signatário. Vale a pena escrutinar a solidez dos argumentos de natureza legal utilizados.

Assumo aqui, acompanhando a reflexão de Lorea (2006), que do ponto de vista estritamente jurídico não existe qualquer impedimento à descriminalização do aborto. Segundo ele, o artigo $5^{\circ}$ da Constituição Federal de 1988, 
que garante o direito à vida a todos os brasileiros e estrangeiros residentes no país, não agasalhou a proteção à vida desde a concepção.

Lorea (2006) alude ainda à superficialidade dos argumentos jurídicos contrários ao direito ao aborto invocados com base na adesão do Brasil a tratados internacionais, como o Pacto de San Jose da Costa Rica, em cujo artigo $4^{\circ}$ se lê: "Toda pessoa tem o direito de que se respeite sua vida. Esse direito deve ser protegido pela lei e, em geral, desde o momento da concepção". Ele argumenta que o pacto em questão curvou-se aos códigos penais vigentes que previam as hipóteses de aborto legal quando da sua aprovação.

Ao esforço de proibição geral do aborto, o Estatuto também visa interditar, como veremos, as situações específicas já previstas em lei e a decisão do Supremo Tribunal Federal que legalizou a interrupção da gravidez de fetos anencéfalos.

\section{A proibição do aborto em caso de anencefalia e de estupro ${ }^{3}$}

No art. 9", o PL 478 destaca "ser vedado ao Estado e aos particulares discriminar o nascituro, privando-o da expectativa de algum direito, em razão de sexo, da idade, da etnia, da origem" (BRASIL 2007c). $O$ artigo ainda elenca ser proibida a mesma discriminação em relação a fetos devido à "deficiência física ou mental ou da probabilidade de sobrevida", o que é corroborado pelo texto do artigo $10^{\circ}$, no qual se lê: "O nascituro deficiente terá à sua disposição todos os meios terapêuticos e profiláticos existentes para prevenir, reparar ou minimizar sua[s] deficiências, haja ou não expectativa de sobrevida extra-uterina" (BRASIL, 2007c). O PL 8116/2014 retoma essa mesma questão nos artigos $9^{\circ}$ e $10^{\circ}$ (BRASIL, 2014). Com isso, esses projetos buscam interditar a realização legal de uma das formas de aborto já acolhidas no direito brasileiro: quando é clinicamente determinado que o feto apresenta anencefalia e, portanto, sua vida extrauterina é absolutamente inviável.

Não termina aqui o caráter regressivo do Estatuto, pois ele também busca impedir outra forma de aborto legal já consagrada na legislação brasileira há décadas, qual seja, aquele decorrente do estupro. Isso fica evidente no art. 12 do PL 8116/2014, que afirma ser "vedado ao Estado e aos particulares causar qualquer dano ao nascituro em razão de um ato delituoso cometido por algum dos seus genitores" (BRASIL, 2014). Essa intenção fica ainda mais explícita no artigo 13 do PL 478, onde se lê que "o nascituro

3 Além dos casos de estupro e de feto anencéfalo, há previsão de aborto legal quando existir risco de vida para a gestante. Não ficou evidente na análise do Estatuto como essa terceira situação deveria ser abordada. 
concebido em um ato de violência sexual não sofrerá qualquer discriminação ou restrição de direitos" (BRASIL, 2007c).

Além da interdição legal à interrupção das gestações decorrentes de estupro, esse PL apresenta também um viés assistencial. Talvez seus autores tenham buscado com isso conferir uma feição mais branda aos traços fortemente criminalizantes de seu projeto e atribuir-lhe um aspecto supostamente mais humanitário em relação ao feto e à mulher, especificamente àquela que foi estuprada. Nessa voga, os autores do PL 478/2007 sugerem que o nascituro tenha direito a receber um salário mínimo por mês, até a idade de 18 anos, a título de pensão alimentícia; e a atendimento prioritário nos serviços de assistência pré-natal e nos processos de adoção, caso a mãe não deseje assumir seus cuidados. Já à gestante é conferido o direito de gozar, também prioritariamente, de atendimento psicológico.

Observe-se que nos PLs 1763 e 3748 as delegacias de polícia passam a deter um papel importante no processo de interrupção da gestação em caso de estupro, pois assumiriam duas funções: a primeira, de caráter assistencial, posto que teriam a obrigação de prestar serviços de informação e orientação social; a segunda, mais consistente com seu objeto institucional central, consistiria em iniciar as investigações que corroborariam a "real" existência do estupro, pois "de maneira alguma [...] bastará a simples palavra da mulher registrada em um boletim de ocorrência, alegando ter sofrido violência sexual" como se lê na justificativa do projeto da deputada Jusmari Oliveira (BRASIL, 2007b). Essa proposta se coaduna com e é mais regressiva do que os procedimentos de "produção da verdade" usados nos serviços de aborto legal existentes no país. É certo que diferentes normativas determinam que o relato da mulher vítima de estupro é suficiente para conferir-lhe a possibilidade de realizar o aborto sem necessidade de prévio inquérito policial ou judicial e sem que sobre ela incidam sanções penais. Tal possibilidade, contudo, de modo pleno, somente existe no plano formal. Isto porque

a tecnologia do inquérito não é exclusiva dos poderes judiciários ou policiais; foi também incorporada aos saberes e práticas biomédicas, em particular, para a gestão da vida sob a forma da biopolítica. No caso do aborto legal, a prática do inquérito investiga a verdade do acontecimento da violência e produz os sentidos para a definição da subjetividade da mulher como vitima. (DINIZ et al., 2014, p. 293) 
Concretamente, nos serviços de aborto legal brasileiros são acionados mecanismos de produção da verdade que questionam se de fato a mulher foi estuprada e se existe realmente um nexo causal entre o estupro e a gravidez. Para tanto, diversos profissionais, como médicos, assistentes sociais e psicólogos, buscam averiguar a coerência e consistência do relato das mulheres estupradas e se elas apresentam as características subjetivas de uma "verdadeira" vítima (DINIZ et al., 2014).

Há que se observar que todos os PLs acolhem a ideia de encaminhamento da criança nascida em decorrência de estupro para a adoção, o que evidencia que o valor atribuído às relações filiais é relativo. Dito de outra forma, para os(as) autores(as) dos PLs não importa tanto que pessoas ou instituições vão cuidar da criança, desde que a gestação seja levada a termo.

Outras questões relevantes sobre a proibição da interrupção da gestação decorrente do estupro contidas no Estatuto merecem ser destacadas. Embora não tenham caráter legal, elas propõem uma viragem regressiva nas formas de entender a maternidade e a paternidade. $\bigcirc$ melhor da literatura sobre essa questão tem realçado que trata-se de fenômenos culturais, com dinâmicas e formas de vivenciá-los que se alteram ao longo do tempo nas diferentes formações sociais. De forma simplificada, trata-se de fenômenos pertencentes ao campo da história e não da natureza. $\bigcirc$ Estatuto nega essa perspectiva ao não conceber a maternidade e a paternidade como fenômenos construídos nos marcos das relações entre um homem e mulher e entre estes e uma criança e a sociedade na qual vivem, remetendo-os para a esfera da biologia. Ao estuprador, assim, é conferido o status de "pai", a despeito da violência e do crime que cometeu. $\bigcirc$ mesmo ocorre com a mulher vítima do estupro, que é transformada em "mãe" contra sua vontade, naturalizando-se a experiência da maternidade, que é vista, como se lê no PL 1763/2007, como uma "vocação da mulher". Tudo isso se inscreve em uma tendência mais ampla na qual

- gênero, a sexualidade e a diversidade sexual foram transformados em armas de uma guerra político-moral no contexto da chamada "ideologia de gênero", bem como dos esforços narrativos visando uma "re-naturalização" do corpo, do sexo e do desejo. Tais esforços se embasam em leituras e interpretações de textos religiosos ora precárias, ora francamente interessadas, e visam disseminar um preconceito reativo contra conquistas importantes das mulheres e da população LGBTI. (CÉSAR; DUARTE, 2017, p. 144). 
Tendo em vista a naturalização da maternidade, da paternidade e da figura do pai e da mãe, não causa estranheza que a desobediência às normas de gênero seja alvo de "criminalização".

\section{O Estatuto e a criminalização}

Os diferentes PLs contêm propostas criminalizantes direcionadas às mulheres que pretendem praticar o aborto e àqueles(as) que se envolvem em experimentos científicos com embriões, como se vê no artigo 25 do PL 478, o qual determina pena de prisão de um a três anos e pagamento de multa para quem "congelar, manipular ou utilizar nascituro como material de experimentação" (BRASIL, 2007c).

Os projetos de lei examinados reconhecem os problemas associados à gravidez decorrente do estupro mas, ao mesmo tempo, advogavam, em estratégia regressiva, a criminalização do aborto realizado nessa circunstância. A deputada Jusmari Oliveira, na justificativa do PL 1763/2007, diz que a inexistência de "punição para o aborto em tal caso (art. 128 inciso II do Código Penal) é uma vergonha nacional" (BRASIL, 2007b). Por isso, - Estatuto tenta criar a figura jurídica do aborto culposo, que seria aplicável à divulgação de procedimentos ou de substâncias abortivas. No limite, pretende-se também tratar o aborto como crime hediondo, com severas implicações práticas para os(as) acusados(as)/condenados(as). Ao propor - endurecimento das penas para a realização do aborto, o Estatuto critica a suposta brandura que lhe é conferida na esfera criminal, o que revelaria "desvalor pela vida da criança por nascer" (BRASIL, 2007b).

As propostas de criminalização não buscam atacar apenas as mulheres que interrompam a gravidez e as pessoas que eventualmente concorram para sua consecução, seja ajudando materialmente, seja "induzindo" a sua prática. Avançam também em direção aos movimentos sociais engajados na luta pela liberalização do aborto. Os indivíduos envolvidos nessa luta ficariam obrigados, se considerados culpados de fazer apologia ou incitar a prática do aborto, ao pagamento de multa e detenção de seis meses a um ano, conforme propõe o art. 28 do PL 478 (BRASIL, 2007c).

No Estatuto, tal criminalização é consistente com tendências mais amplas da sociedade brasileira. Sobre esse tema, vale a pena tecer algumas considerações. A criminalização faz parte de uma malha teórica e institucional que envolve a "penalização", o "proibicionismo", o "punitivismo", a "patologização" e a "medicalização", malha que pode ser visualizada em distintos momentos e 
áreas da história de diversas formações sociais. Seu caráter histórico faz com que a reprovação/aprovação do uso de dado produto, como se vê na história da utilização do ópio, ou a execução de uma determinada prática, como o infanticídio, devam ser considerados temporários e reversíveis.

Embora não se possa estabelecer relações umbilicais, a criminalização e os processos a ela interligados podem ser associados a interesses diversos, inclusive econômicos, como se vê em situações ligadas ao comércio de produtos que em determinadas quadras históricas foram considerados lícitos e saudáveis. A indústria farmacêutica e a indústria de alimentos têm exemplos cristalinos sobre como a proibição e criminalização (ou o movimento inverso) de determinadas substâncias e comportamentos podem ser extremamente lucrativas. As drogas são exemplo ainda mais contundente, pois a relação entre a criminalização, o proibicionismo e a lucratividade já está bem estabelecida. Sobre este exemplo, vale a pena transcrever a seguinte análise:

Enfim, a qualificação das drogas que podem ou não ser usadas e a construção de políticas repressivas geram efeitos contrários aos que o discurso proibicionista defende, e por mais que se proíba, o uso não cessa. Fernandez (1997, p. 120), aponta que o proibicionismo cria novas questões associadas ao uso de substâncias psicoativas e, especialmente, agrega valor à mercadoria. Segundo ele, "as drogas são mercadorias, cuja proibição vem possibilitando lucros extraordinários e consolidando uma poderosa economia ilegal”. (ROCHA, 2013, p. 568).

Associada ao atendimento de interesses econômicos está a tendência em descolar fenômenos tidos hoje como violentos, passiveis de ação penal e de abrangência coletiva dos contextos sociais e políticos nos quais se inscrevem. Como salienta Xavier (2008, p. 275):

\footnotetext{
Pensar as questões da violência é, muitas vezes, relacioná-las com o crime, o criminoso e a sensação de insegurança. Comumente desse debate, excluem-se as demais relações que promovem ou contribuem para as expressões da violência, sejam elas de classe, sociais, econômicas ou históricas.
}

Comentando a mesma questão, Rocha salienta a existência de discursos sobre a criminalidade eivados de um moralismo exacerbado e de "extrema ausência de historicidade para a compreensão das raízes da criminalidade como um fenômeno que deve ser entendido a partir da contextualização sócio-histórica" (2013, p. 563). Dito de outra forma, com variações ao 
longo do tempo, o chamado "ato criminoso" é descolado dos contextos e estruturas sociais nos quais se inscreve e é remetido ao campo das características psicológicas ou morais de um dado indivíduo ou grupo. Traz-se, com isso, "para o centro do debate a figura do criminoso, deixando a problemática da criminalidade em segundo plano" (XAVIER, 2008, p. 275).

A figura do "criminoso" não diz respeito a qualquer pessoa. Ela é encarnada na imagem do pobre, do favelado, do negro etc., deixando de fora os individuos ligados às classes dominantes. $\bigcirc$ "criminoso" também encarna na figura de crianças e adolescentes pobres, o que muitas vezes funciona como justificativa para reduzir a maioridade penal (ROCHA, 2013; XAVIER, 2008). Certos grupos étnicos minoritários também são alvos, como destacou Delmanto (2010) ao analisar o combate ao consumo de substâncias proibidas nos Estados Unidos (o ópio dos chineses, a maconha dos mexicanos e a cocaína dos negros), revelando que o proibicionismo e a criminalização têm um componente étnico e racial. Ainda sobre o processo de criminalização, cabe destacar que ele opera desde uma lógica dualista (e maniqueísta) que opõe o bem (o cidadão correto ou normal) e o mal (o indivíduo incapaz de conter suas inclinações para o crime).

Tudo isso cria uma tendência, no campo das investigações e da produção de políticas públicas, de tomar como ponto de partida das reflexões e ações os traços psicológicos dos indivíduos supostamente mais inclinados à criminalidade. Isso é bastante visível no caso do uso de drogas. Ao abordar essa questão, Silva e Delduque salientam que a atuação do poder legislativo "contribui para sua penalização e patologização, mais do que para sua politização" (2014, p. 231). A politização nesse caso significaria remeter a discussão à arena pública, onde atores movidos pelos mais diferentes interesses e valores pudessem estabelecer um confronto dialogal sempre aberto. A penalização e a patologização, ao contrário, expressam a opção pela interdição, por um longo tempo, do debate sobre dada questão, o qual somente seria reaberto em face, geralmente, de circunstâncias disruptivas.

É o que poderia acontecer caso fossem aprovados os PLs que compõem o Estatuto do Nascituro, num esforço de seus autores para acentuar a dimensão criminalizante e punitiva da legislação brasileira sobre o aborto. Busca-se penalizar o ato, os agentes envolvidos e a própria discussão sobre o aborto legal, vista exclusivamente como propaganda, em detrimento da necessária reflexão sobre (1) a minguada e restritiva legislação sobre a questão; 
(2) as circunstâncias peculiares e precárias de sua materialização; e (3) a aludida necessidade de ampliar e manter esse debate na arena pública.

\section{O Estatuto e o pânico moral}

As proposituras de legislação mais punitiva para o aborto, em particular, e o conjunto das propostas contidas nos PLs, em geral, têm uma dupla função. A primeira, mais visível, é construir as bases legais que dificultem ou impeçam o usufruto de direitos sexuais e reprodutivos. A segunda função é servir como ponto de partida para difundir ideias e valores conservadores sobre o tema. Isso, ao seu turno, é feito valendo-se de estratégias discursivas que utilizam a criação de um "pânico moral", entendido como um

artificially created panic or scare. Researchers, often influenced by critical conflict-oriented Marxist themes, have demonstrated that moral entrepreneurs have demonized "dangerous groups" to serve their own religious, political, economic, social, cultural, and legal interests. Although the aims, forms, dynamics, and outcomes of moral panics vary throughout history, they have, with isolated exceptions, been initiated by powerful interest groups to manage the bodies and behavior of threatening groups - often, the poor and powerless. (PISCIOTTA, 2018).

No caso dos defensores do Estatuto, observa-se a utilização de termos fortemente carregados de apelo emocional, os quais cumprem dupla função: de um lado, estimulam sentimentos piedosos em relação ao feto ou "nascituro", tomado como vítima de assassinato cruel; de outro, antagonizam a sociedade e as pessoas consideradas irresponsáveis e desumanas que estejam envolvidas na prática do aborto. Ao mesmo tempo, buscam causar repugnância ao descrever o modo como o aborto ocorre. Eis algumas expressões utilizadas pelo Estatuto para tal fim: "bebê esquartejado"; "aspirado em pedacinhos"; "envenenado por uma solução que lhe corrói a pele"; "deixado morrer à míngua"; "ação direta para acabar de matá-los"; "executado"; "condenado sumariamente à pena de morte"; "assassínio"; "asfixiaram o bebê"; "violência contra seres indefesos".

4 A criação de um clima de pânico moral é consistente com os processos de criminalização. Para que este ocorra faz-se necessário manter uma ambiência na qual o medo, em maior ou menor grau, esteja presente. É o medo, em sua generalização, que afiança a tomada de medidas restritivas de liberdade individual e coletiva, a criminalização de certas práticas e as propostas de retirada de direitos. Esse contexto favorece a manutenção do "sentimento de perigo (sentimento subjetivo de insegurança), gerando indignação e consensos silenciosos entre os setores sociais" (XAVIER, 2008, p. 272). 
Um ator exerce papel preponderante para o sucesso das estratégias de pânico moral: a mídia. Nas suas diversas expressões, ela tem hoje a capacidade de disseminar, em ritmo acelerado, informações que, com inusitada frequência, são inverídicas. Embora seja necessário reconhecer, de um lado, que as pessoas possuem capacidade crítica em relação às informações que lhes são apresentadas, por outro lado, as diferentes mídias operam de forma tentacular, envolvendo ponderáveis setores da população em um campo discursivo do qual é difícil descolar-se. Nesse campo são construídos argumentos e descrições que ganham a força de uma doxa, de fatos materiais incontestes (BOURDIEU, 1991). À mídia juntam-se diversas outras instituições formadoras de opinião e crenças, a exemplo da escola (BOURDIEU, 1998).

No Estatuto, as estratégias argumentativas utilizadas para produzir pânico moral em relação à interrupção da gestação decorrente de estupro incluíam ainda: (1) a defesa da ideia de que o aborto perfaz uma punição para o nascituro e não para o "pai" estuprador e (2) a certeza da existência de danos para as mulheres estupradas que decidem abortar. Argumentos pseudocientíficos são elencados para mostrar supostas vantagens à mulher para que dê prosseguimento à gestação nessa circunstância. Na justificativa do PL 1763/2007, por exemplo, lê-se que "se no futuro, a mulher se casa e tem outros filhos, o filho do estupro costuma ser preferido. Tal fato tem uma explicação simples na psicologia feminina: as mães se apegam de modo especial aos filhos que thes deram maior trabalho" (BRASIL, 2007b). Inversamente, alude-se que a vítima do estupro é facilmente influenciada por "aborteiros" que

causarão, não apenas a morte do inocente, mas o aniquilamento psíquico da mãe, que carregará para sempre o trauma da morte do filho. É difícil imaginar algo que seja mais danoso para a mulher violentada do que a indescritivel síndrome pós-aborto, capaz de levar muitas delas ao suicídio. (BRASIL, 2007b, grifo nosso).

A experiência do aborto pode efetivamente ser traumática para muitas mulheres que o praticam, o que deve ser associado às circunstâncias materiais e à reprovação social ainda ligada à cessação da gravidez. Contudo, a literatura especializada não afiança que levar a termo uma gestação decorrente de estupro ou indesejada por algum outro motivo é algo intrinsecamente positivo para as mulheres. 


\section{O Estatuto, a "pílula do dia seguinte", embriões in vitro e pesquisas com células-tronco}

Subsidiariamente à proibição do aborto, o Estatuto também busca restringir o acesso à pílula do dia seguinte na rede pública e em estabelecimentos privados. Isso ocorre através do Projeto de Lei 1413/2007, que busca alterar a Lei $9.263 / 96$, que trata do planejamento familiar. $\bigcirc$ texto de tal projeto afirma que a referida lei, como implementada, desviou-se de seu objetivo principal, pois oferecer anticoncepção de emergência nos serviços de saúde é um disfarce para assegurar a legalidade de práticas abortivas. O PL utiliza argumentos para mostrar que a sobreposição entre a anticoncepção de emergência e o aborto parece lógica, desde que se acolha a concepção de nascituro já aqui descrita. No corpo dessa discussão - a alegada sobreposição entre aborto e anticoncepção - situam-se também os esforços de controle da sexualidade dos jovens. Estes, principalmente quando pobres, em um viés já conhecido, são vistos como portadores de uma sexualidade descontrolada. Não se trata de negar a existência de questões relevantes relacionadas à vida sexual e reprodutiva - a gravidez na adolescência e as doenças sexualmente transmissiveis, por exemplo - desse segmento da população. Mas sim de examinar tais questões desde uma perspectiva de saúde pública e não de moralização da sexualidade, como se avista no Estatuto.

Estatuto também considera um "nascituro" os embriões gerados por clonagem ou in vitro, "mesmo antes da transferência para o útero da mulher" (BRASIL, 2014). Estes são, assim, portadores dos mesmos direitos dos já nascidos e dos que se encontram em gestação em útero. A amplitude dessa definição de nascituro tem como objetivo impedir o descarte de embriões, prática comum em clínicas especializadas de reprodução assistida. Igualmente, busca incidir nas pesquisas com células-tronco que também se servem de embriões gerados dessa forma. Na justificativa do PL 478 essa discussão é expressa de forma objetiva. Dizem-nos os autores que

a proliferação de abusos com seres humanos não nascidos, incluindo a manipulação, o congelamento, o descarte e o comércio de embriões humanos, a condenação de bebês à morte por causa de deficiências físicas ou por causa de crime cometido por seus pais, os planos de que os bebês sejam clonados e mortos com o único fim de serem suas células transplantadas para adultos doentes, tudo isso requer que, a exemplo de outros países como a Itália, seja promulgada uma lei que ponha um "basta" a tamanhas atrocidades. (BRASIL, 2007c). 


\section{Considerações finais}

Embora o Estatuto do Nascituro tenha sido examinado por diferentes comissões da Câmara Federal ao longo de dez anos, nunca foi objeto de deliberação final, tendo sido arquivado. As ideias nele contidas, todavia, permanecem em circulação no Congresso Nacional. Por isso, não foi surpreendente que, em 16 de maio de 2017, a Comissão de Constituição e Justiça do Senado da República tenha retomado seu conteúdo sob a forma da Proposta de Emenda Constitucional (PEC) 29/2015, de autoria do senador Magno Malta (Partido da República/ES - evangélico) e subscrita por mais de 27 senadores. Em termos práticos, essa PEC, em cujo artigo $1^{\circ}$ se lê que "todos são iguais perante a lei, sem distinção de qualquer natureza, garantindo-se aos brasileiros e aos estrangeiros residentes no País a inviolabilidade do direito a vida desde a concepção, à liberdade, à segurança e à propriedade" (BRASIL, 2015, grifo nosso), transforma em crime todas as formas de interrupção da gravidez já previstas na legislação atual. O parecer do senador Eduardo Amorim (PSDB/SE - católico) foi favorável à aprovação da PEC, salientando que ela favorece o princípio do respeito à vida insculpido na Constituição Federal e em tratados internacionais dos quais o Brasil é signatário. Não é possivel prever os rumos que essa PEC tomará no Senado.

Não é difícil sustentar a hipótese de que no atual contexto de aprofundamento do conservadorismo, tanto no campo legislativo como na sociedade por inteiro, as propostas contidas no Estatuto possam vir a serem aprovadas. Entretanto, o vigor dos movimentos sociais e a franca oposição de importantes setores da sociedade colocam barreiras significativas a essa possibilidade. Com efeito, acreditamos que os próprios proponentes do Estatuto, nas suas diversas filiações partidárias e, principalmente, religiosas, vendo as limitações impostas à sua aprovação, insistam na discussão tendo em mente outro objetivo capaz de gerar ganhos políticos nada despreziveis. Trata-se da possibilidade de manter, ao longo de anos, o debate contra o aborto na sociedade brasileira. Com isso, não só vocalizam suas posições mas, principalmente, criam uma subarena pública na qual setores da população que aderem aos princípios do Estatuto encontram espaço para vocalizar sem reservas suas opiniões. Está em questão a formação de uma coalização discursiva à qual vão aderindo diferentes agentes, desde altos membros da hierarquia eclesiástica e dos três poderes da República, comunicadores que contam com grande audiência, personalidades do mundo artístico etc. até, principalmente, o cidadão comum que faz parte do que se convencionou 
chamar de "maioria silenciosa". Estes, em particular, mas também o conjunto de atores aludido, passaram a vocalizar de modo mais estruturado e frequente sua oposição em relação às possibilidades já existentes de aborto legal e a expressar sua adesão a políticas regressivas no campo dos direitos sexuais e reprodutivos, reforçando seu lugar instável na agenda pública.

Lidar com essecenário é tarefa extremamente complexa que não pode ser orientada por propostas simplistas. O filósofo estadunidense Richard Rorty (1999) e outros pensadores franceses que discutem a laicidade têm destacado a importância de privatizar cada vez mais a religião, retendo-a no âmbito dos templos e das famílias. Assim, valores particularistas não teriam sua existência proibida, mas sua difusão seria mantida nas cercanias dos espaços privados aludidos. Consequentemente, se não fosse possível eliminá-los, ao menos se reduziria a incidência de ideias de cunho religioso e outras idiossincrasias sobre as discussões de ordem pública e coletiva. Tais discussões seriam encaminhadas desde uma perspectiva laica, respeitando, por conseguinte, no caso do Brasil, o que prescreve a Constituição Federal de 1988 quanto à separação entre o Estado e as religiões.

Se para os Estados Unidos da América e para boa parte dos países europeus isso pode parecer uma obviedade, não se pode dizer o mesmo em relação ao nosso país, pois não contamos com uma longa história de liberdades políticas e civis. Ao contrário, nossa história pode ser associada muito mais ao silenciamento de importantes atores sociais do que ao estímulo à formação de uma esfera pública na qual as diferentes vozes possam se manifestar. Embora não seja o único exemplo, vale lembrar que nossa democracia, construída desde o fim do império, foi entremeada por regimes ditatoriais de longa duração. Só isso é suficiente para que sejam tomadas precauções quanto à privatização de ideias, mesmo as que consideramos regressivas. Em certo sentido, creio que a longo prazo é mais salutar para a consolidação da democracia brasileira que elas sejam amplamente vocalizadas e confrontadas com as opiniões divergentes no espaço público ${ }^{5}$. Nesse fazer, pelo menos uma precaução é fundamental: não reproduzir, a propósito da defesa da laicidade estatal, preconceitos sobre credos religiosos. Expressões utilizadas no

\footnotetext{
5 Esse argumento é ainda mais forte quando se leva em consideração as divergências internas existentes entre as denominações assim como as disputas intrainstitucionais. Ainda que óbvio, também não se pode deixar de salientar que não existe uma adesão uniforme dos membros (e mesmo dos ocupantes das mais altas posições) de um dado credo às ideias preconizadas por ele. Tais membros podem concordar plenamente, mas também podem divergir no todo ou em parte em relação à doutrina pregada. No caso do aborto, como lembra Lorea (2006, p.188), "78\% dos católicos (contra 74\% da população em geral) são favoráveis à oferta de aborto legal nos serviços públicos de saúde."
} 
embate político entre as ideias laicas e as ideias religiosas precisam ser qualificadas, evitando-se utilizar, por exemplo, expressões derrogatórias ("evanjegues" é uma bastante comum) contra segmentos protestantes. Igual cuidado, agora de caráter mais amplo, deve ser tomado em relação à criação de um clima anticlerical no qual as religiões de matriz judaico-cristã, apesar da grande quantidade de diferentes capitais que possuem, sejam alvo de qualquer forma de discriminação ou perseguição.

Um último comentário. As propostas do Estatuto receberam amplo apoio de parlamentares situados à direita e no centro do espectro político, o que não causa surpresa. Chama atenção, contudo, que alguns dos projetos de lei que o compõem tenham sido encabeçados ou apoiados por parlamentares de partidos tradicionalmente situados à esquerda e com histórico de defesa dos direitos das mulheres e das minorias sociais em geral. Tal fato aumenta a complexidade da discussão, mostrando que não são apenas os religiosos que se unem em torno das questões morais. Setores da direita e da esquerda, em temas como o aborto, criam alianças potentes capazes de desconstruir o lugar conquistado na agenda pública pelos direitos sexuais e reprodutivos.

\section{Referências}

BARCHIFONTAINE, C. P. Bioética no início da vida. Pistis \& Praxis, Curitiba, v. 2, n. 1, p. 41-55, 2010.

BRASIL. Câmara dos Deputados. Projeto de Lei n ${ }^{0}$ 1413, de 26 de junho de 2007. Dá nova redação ao parágrafo único do art. $6^{\circ}$ e ao parágrafo único do art. $9^{\circ}$, ambos da Lei $n^{\circ}$ 9.263, de 1996, que regula o $\S 7^{\circ}$ do art. 226 da Constituição Federal. Brasilia, DF: Câmara dos Deputados, 2007a. Autor: Luiz Bassuma. Disponivel em: https://bit.ly/38jGInn. Acesso em: 1 jul. 2020.

BRASIL. Câmara dos Deputados. Projeto de Lei n ${ }^{0}$ 1763, de 14 de agosto de 2007. Dispõe sobre o Estatuto do Nascituro e dá outras providências. Brasília, DF: Câmara dos Deputados, 2007b. Autora: Jusmari Oliveira. Disponivel em: https://bit.ly/2NOxCjC. Acesso em: 1 jul. 2020.

BRASIL. Câmara dos Deputados. Projeto de Lei n 3748, de 16 de julho de 2008. Autoriza o Poder Executivo a conceder pensão à mãe que mantenha a criança nascida de gravidez decorrente de estupro. Brasília, DF: Câmara dos Deputados, 2008. Autora: Sueli Vidigal. Disponivel em: https://bit.ly/2CRC5zR. Acesso em: 1 jul. 2020. 
BRASIL. Câmara dos Deputados. Projeto de Lei n 478, de 19 de março de 2007. Dispõe sobre o Estatuto do Nascituro e dá outras providências. Brasilia, DF: Câmara dos Deputados, 2007c. Autores: Luiz Bassuma e Miguel Martini. Disponivel em: https://bit.ly/3dSdisq. Acesso em: 1 jul. 2020.

BRASIL. Câmara dos Deputados. Projeto de Lei n 489, de 20 de março de 2007. Dispõe sobre o Estatuto do Nascituro e dá outras providências. Brasília, DF: Câmara dos Deputados, 2007d. Autor: Odair Cunha. Disponível em: https://bit.ly/2VyXsfJ. Acesso em: 1 jul. 2020.

BRASIL. Câmara dos Deputados. Projeto de Lei $\mathbf{n}^{0}$ 8116, de 19 de novembro de 2014. Dispõe sobre a proteção ao nascituro. Brasilia, DF: Câmara dos Deputados, 2014. Autores: Alberto Filho, Arolde de Oliveira e Aníbal Gomes. Disponivel em: https://bit.ly/3giEMZE. Acesso em: 1 jul. 2020.

BRASIL. Senado Federal. Proposta de Emenda à Constituição $n^{\circ} 29$, de 2015. Altera a Constituição Federal para acrescentar no art. $5^{\circ}$, a explicitação inequívoca "da inviolabilidade do direito à vida, desde a concepção. Brasilia, DF: Senado Federal, 2015. Disponivel em: https://bit.ly/3dQbkZE. Acesso em: 1 jul. 2020.

BOSCHETTI, I. Avaliação de políticas, programas e projetos sociais. In: CFESS; ABEPSS. (org.). Serviço social: direitos sociais e competências profissionais. Brasilia, DF: CFESS, 2009. p. 575-591.

BOURDIEU, P. Language and symbolic power. Cambridge: Harvard University Press, 1991.

BOURDIEU, P. The state nobility: elite schools in the field of power. Stanford: Stanford University Press, 1998.

CÉSAR, M. R. A.; DUARTE, A. M. Governamento e pânico moral: corpo, gênero e diversidade sexual em tempos sombrios. Educar em Revista, Curitiba, n. 66, p. 141-155, 2017.

DELMANTO, J. Imperialismo e proibicionismo: raízes e interesses da proibição das drogas e da suposta guerra ao tráfico. [S. I.]: Neip, 2010.

DINIZ, D. et al. A verdade do estupro nos serviços de aborto legal no Brasil. Revista Bioética, Brasilia, DF, v. 22, n. 2, p. 291-298, 2014. 
GIUMBELLI, E. A presença do religioso no espaço público: modalidades no Brasil. Religião e Sociedade, Rio de Janeiro, v. 28, n. 2, p. 80-101, 2008.

KINGDON, J. W. Agendas, alternatives, and public policies. Boston: Little Brown, 1984.

LOREA, R.A. Acesso ao aborto e liberdades laicas. Horizontes Antropológicos, Porto Alegre, v. 12, n. 26, p. 185-201, 2006.

ORO, A. O. A política da Igreja Universal e seus reflexos nos campos religioso e político brasileiros. Revista Brasileira de Ciências Sociais, São Paulo, v. 18, n. 53, p. 53-69, 2003.

PISCIOTTA, A. Moral panic. In: Encyclopædia Britannica. London: Encyclopædia Britannica, 2018.

ROCHA, A. P. Proibicionismo e a criminalização de adolescentes pobres por tráfico de drogas. Serviço Social e Sociedade, São Paulo, n. 115, p. 561-580, 2013.

RORTY, R. Religion as a conversation stopper. In: RORTY, R. Philosophy and social hope. New York: Penguin, 1999. p. 168-174.

SECCHI, L. Políticas públicas: conceitos, esquemas de análise, casos práticos. São Paulo: Cengage Learning, 2010.

SILVA, M. B.; DELDUQUE, M. C. Patologização e penalização do uso de drogas: uma análise socioantropológica de proposições legislativas (2007-2010). Physis, Rio de Janeiro, v. 25, n. 1, p. 231-250, 2015.

XAVIER, A. A construção do conceito de criminoso na sociedade capitalista: um debate para o Serviço Social. Revista Katálysis, Florianópolis, v. 11, n. 2, p. 274-282, 2008.

Recebido em fevereiro de 2020.

Aceito em abril de 2020. 